\title{
$0=$

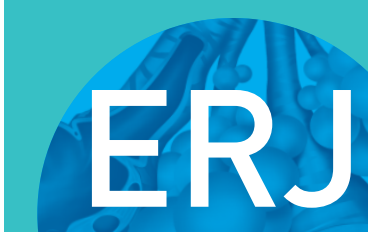 \\ Economic consequences of idiopathic pulmonary fibrosis in Denmark
}

open research

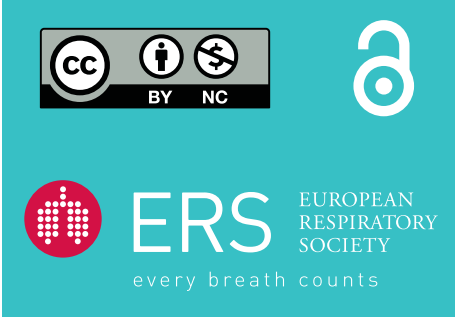

\section{To the Editor:}

Idiopathic pulmonary fibrosis (IPF) is the most common of the idiopathic interstitial lung diseases (ILDs) and carries a poor prognosis. The recent therapeutic achievements have changed the management of the disease $[1,2]$ and increased the need for health economy evaluations. However, only a few studies have examined the economic consequences of IPF $[3,4]$. The aim of the present study was: 1) to evaluate the health economic aspects of IPF in well-characterised patients diagnosed in accordance with the current evidence-based guidelines before the introduction of antifibrotic therapy [5]; and 2) to compare the health-related costs of IPF and matched controls from the general population using prospectively collected data from population-based medical databases in the predominantly tax-financed Danish healthcare system.

The study population included 120 patients diagnosed with IPF at Aarhus University Hospital, Aarhus, Denmark (one of three national ILD centres) between 2003 and 2009. Clinical parameters were obtained from the ILD registry at our institution. Mean age was 66.5 years, $77 \%$ of the patients were male, forced vital capacity was $69.8 \%$ pred and diffusing capacity of the lung for carbon monoxide was $41.5 \%$ pred. Prior to inclusion into the ILD registry, all patients underwent diagnostic re-evaluation according to the current diagnostic criteria [5]. Characteristics of the cohort were reported previously [6]. By linking the IPF cohort to the Danish National Patient Register, we obtained information on all hospital admissions and outpatient contacts. IPF patients were matched 1:4 for age, sex and educational level with randomly selected controls from the Civil Registration System. We selected control subjects who lived in the same part of the country and had the same marital status as the patients in order to minimise social status bias. Information on educational level was obtained for $96 \%$ of the subjects aged 14-80 years. Patients and controls were followed from 1998 to 2010.

The Civil Registration System contains information about date of birth, place of residence, vital status and migration into or out of Denmark since 1968 [7]. The central person registry number assigned to all residents enables individual level linkage across registries. The system ensures complete follow-up with respect to mortality. The Danish National Patient Registry contains information about all hospital contacts including emergency room visits, outpatient visits, hospital admittances and the related primary and secondary diagnoses [8]. The National Health Insurance registers all contacts in general and specialist practice, and provides information of the frequency and costs of consultations with general practitioners and other medical specialists. The Danish Medicines Agency registers the use of prescription drugs, and provides the retail price of each drug, including dispensing costs and number of transactions. Statistics Denmark provides information about marital status, educational level, employment income and pensions. The Danish Ministry of Health provided the specific costs of hospital admissions and outpatient contacts. The study was approved by the Danish Data Protection Agency and the Health Data Authority.

We determined the annual healthcare costs per patient and compared these figures with annual healthcare costs in the matched control group.

Direct costs included the costs of hospitalisation based on Diagnosis Related Groups and costs of outpatient contacts based on the assigned fixed rate per visit. The calculation was performed using data

@ERSpublications

When a patient is diagnosed with IPF, the net health costs increase from $€ 2753$ to $€ 21184$ per year even without the cost of antifibrotic treatment. Inpatient treatment accounts for the main part of the expenses http://ow.ly/dSsn30jEx0p

Cite this article as: Hilberg $\mathrm{O}$, Bendstrup E, Ibsen $\mathrm{R}$, et al. Economic consequences of idiopathic pulmonary fibrosis in Denmark. ERJ Open Res 2018; 4: 00045-2017 [https://doi.org/10.1183/ 23120541.00045-2017].

Copyright $\odot$ ERS 2018. This article is open access and distributed under the terms of the Creative Commons Attribution NonCommercial Licence 4.0. 
from the Ministry of Health. Medication costs were obtained from the Danish Medicines Agency. The costs of consultations with general practitioners and other non-hospital-based specialists were obtained from the National Health Insurance.

Indirect costs included unemployment benefits and social transfer payments based on income figures from Statistics Denmark. The costs were measured on an annual basis and adjusted to 2010 prices in euros $(€ 1=7.45 \mathrm{DKK})$.

The results are presented as mean values. This approach was chosen because the resource consumption was very high for some patients, and it would not be adequately represented if data were presented as median values. Extreme values were manually validated and no errors were identified. Statistical significance of the cost estimates was assessed by nonparametric bootstrap analysis [9]. Survival was estimated using the Kaplan-Meier method. Hazard rate ratios were calculated using Cox proportional hazards regression analysis. Statistical analysis was performed using SAS (version 9.1.3; SAS Inc., Cary, NC, USA).

Before the IPF diagnosis no difference was seen in costs of inpatient treatment, employment income or public transfer payments between IPF patients and matched controls.

After the IPF diagnosis the costs of inpatient treatment increased almost 10-fold compared with matched controls, and the employment income for IPF patients was only half of what it was in the control group. Public transfer income was slightly higher in the first year after the diagnosis compared with controls, but afterwards no difference was seen. Altogether, an abrupt and persisting increase in the total costs was observed.

The net cost was calculated as the difference between total costs and public transfer payments in the two groups. After the IPF diagnosis, the net cost increased from $€ 2753$ to $€ 21184$ per year, which is equivalent to a seven-fold increase. The inpatient treatment accounted for the main part of the expenses but, because of the decrease in employment income, indirect costs also contributed. The results are shown in table 1.

We estimated the total costs related to IPF based on a cohort of patients with re-evaluated diagnoses before the introduction of antifibrotic therapy. The costs were compared with the costs related to age-, sexand education-matched controls. A seven-fold increase in net costs was seen after the diagnosis of IPF.

A previous incidence estimate of IPF in Denmark (5.6 million inhabitants in 2016) was 1.3 per 100000 [6]. Based on data from national medical registries, the overall incidence of ILDs in Denmark is 15.8 per 100000 [10]. Approximately one-third of these patients have IPF, and the corresponding incidence of IPF is 5 per 100000 . Assuming a median survival of 4 years, this corresponds to $300-1000$ prevalent IPF patients in Denmark resulting in IPF-related costs of $€ 6.4$ to $€ 20$ million per year. Several studies indicate that the prevalence of IPF is increasing, most probably due to the ageing population [11, 12]. Therefore, the socioeconomic burden related to IPF may increase further in the future.

Before the diagnosis, only the medication costs were slightly higher in the IPF group. This may be explained by delayed diagnosis $[6,13]$ and treatment based on suspicion of other pulmonary diseases, e.g. infection and chronic obstructive pulmonary disease (COPD), during this time [13].

TABLE 1 Health costs and income in euros before and after a diagnosis of idiopathic pulmonary fibrosis (IPF) diagnosis

\begin{tabular}{|c|c|c|c|c|c|c|}
\hline & \multicolumn{3}{|c|}{ Before } & \multicolumn{3}{|c|}{ After } \\
\hline Inpatient treatment & $1040 \pm 3785$ & $904 \pm 3740$ & 0.970 & $14683 \pm 18440$ & $1528 \pm 5500$ & $<0.0001$ \\
\hline Outpatient treatment & $266 \pm 567$ & $223 \pm 1198$ & 0.302 & $1198 \pm 3314$ & $426 \pm 1673$ & $<0.0001$ \\
\hline Medication & $481 \pm 630$ & $391 \pm 700$ & 0.001 & $1151 \pm 1300$ & $534 \pm 830$ & $<0.0001$ \\
\hline National Health Insurance & $243 \pm 231$ & $246 \pm 339$ & 1.0 & $464 \pm 476$ & $325 \pm 372$ & $<0.0001$ \\
\hline Direct costs ${ }^{\#}$ & 2030 & 1764 & & 17495 & 2813 & \\
\hline Public transfer payments ${ }^{+}$ & 10726 & 10194 & & 12478 & 11653 & \\
\hline Total costs ${ }^{\S}$ & 3985 & 1764 & & 23173 & 2813 & \\
\hline Net costs ${ }^{f}$ & \multicolumn{2}{|c|}{2753} & & \multicolumn{2}{|c|}{21184} & \\
\hline
\end{tabular}

Data are presented as mean \pm SD or mean value per individual, unless otherwise stated. \#: the sum of inpatient treatment, outpatient treatment, medication and national health insurance; ${ }^{\text {ๆ: }}$ the difference in employment income between cases and controls; ${ }^{+}$: the sum of pensions, other public transfer payments and publicly funded sickness benefits; ${ }^{\S}$ : sum of direct and indirect costs; $^{f}$ : the difference between direct costs, indirect costs and public transfer payments. 
In a recent study of 131811 Danish COPD patients based on the same model as the present study [14], the annual net costs, including social transfer payments, were $€ 8572$. This is approximately one-third of the cost of IPF. The huge difference in the size of the study populations complicates the direct comparison of the two diseases. However, the reason for the difference in costs may be the rapidly progressive nature of IPF. A large proportion of IPF patients will need hospital admission because of respiratory failure whereas more COPD patients have relatively stable disease with fewer hospital contacts. This is supported by a recent study from Spain [15] where the authors estimated the annual cost per patient with IPF separated into categories of stable disease, slow and rapid disease progression, and reported significantly higher costs related to rapid disease progression.

Antifibrotic therapy was not available in Denmark during the study period. The costs of medication have increased considerably since 2011 when antifibrotic therapy became available. Improved management strategies and therapies may be able to reduce other health-related costs related to hospitalisations and exacerbations but, at present, the efficacy of antifibrotic therapy compared to best supportive care comes at a high cost [16]. Another study based on the pirfenidone clinical trials has estimated that antifibrotic medication prolongs survival by 2.47 years [17]. At present it is unclear whether longer survival and increased medication cost are balanced by a decrease in costs related to acute exacerbations and disease progression with severe respiratory insufficiency. Although, the median survival is also poor in COPD (7 years) [14], IPF and COPD are not directly comparable as in a number of patients COPD starts at a younger age, is disabling and affects capability of work, and increases cost of medication and public support. IPF is a serious disease affecting the growing elderly population and future socioeconomic evaluation of the cost-benefit of antifibrotic treatment is essential.

Ole Hilberg ${ }^{1}$, Elisabeth Bendstrup ${ }^{2}$, Rikke Ibsen ${ }^{3}$, Anders Løkke ${ }^{2}$ and Charlotte Hyldgaard $\odot^{2,4}$

${ }^{1}$ Medical Dept, Sygehus Lillebalt Vejle Sygehus, Vejle, Denmark. ${ }^{2}$ Dept of Respiratory Diseases, Aarhus University Hospital, Aarhus, Denmark. ${ }^{3}$ itracks, Aarhus, Denmark. ${ }^{4}$ Diagnostic Centre, Silkeborg Regional Hospital, Silkeborg, Denmark.

Correspondence: Ole Hilberg, Medical Dept, Sygehus Lillebalt Vejle Sygehus, Beridderbakken 2, Vejle, 7100, Denmark. E-mail: ole.hilberg@rsyd.dk

Received: April 042017 | Accepted after revision: April 192018

Conflict of interest: E. Bendstrup has received lecture fees from Intermune, Roche and Boehringer Ingelheim and has participated in four advisory board meetings during the last 5 years. Her hospital has received an unrestricted grant from both Roche and Boehringer Ingelheim.

Support statement: This article was funded by F. Hoffman-La Roche (unrestricted grant from Intermune). Funding information for this article has been deposited with the Crossref Funder Registry.

\section{References}

1 King TE Jr, Bradford WZ, Castro-Bernardini S, et al. A phase 3 trial of pirfenidone in patients with idiopathic pulmonary fibrosis. N Engl J Med 2014; 370: 2083-2092.

2 Richeldi L, du Bois RM, Raghu G, et al. Efficacy and safety of nintedanib in idiopathic pulmonary fibrosis. $N$ Engl J Med 2014; 370: 2071-2082.

3 Loveman E, Copley VR, Colquitt JL, et al. The effectiveness and cost-effectiveness of treatments for idiopathic pulmonary fibrosis: systematic review, network meta-analysis and health economic evaluation. BMC Pharmacol Toxicol 2014; 15: 63-6511-15-63.

4 Collard HR, Ward AJ, Lanes S, et al. Burden of illness in idiopathic pulmonary fibrosis. J Med Econ 2012; 15: 829-835.

5 Raghu G. Idiopathic pulmonary fibrosis: guidelines for diagnosis and clinical management have advanced from consensus-based in 2000 to evidence-based in 2011. Eur Respir J 2011; 37: 743-746.

6 Hyldgaard C, Hilberg O, Muller A, et al. A cohort study of interstitial lung diseases in central Denmark. Respir Med 2014; 108: 793-799.

7 Schmidt M, Pedersen L, Sorensen HT. The Danish Civil Registration System as a tool in epidemiology. Eur J Epidemiol 2014; 29: 541-549.

8 Schmidt M, Schmidt SA, Sandegaard JL, et al. The Danish National Patient Registry: a review of content, data quality, and research potential. Clin Epidemiol 2015; 7: 449-490.

9 Efron B, Tibshirani R. An Introduction to the Bootstrap. London, 1993.

10 Hilberg O, Bendstrup E, Løkke A, et al. Co-morbidity and mortality among patients with interstitial lung diseases: a population-based study. Respirology 2017; in press [https://doi.org/10.1111/resp.13234].

11 Navaratnam V, Fleming KM, West J, et al. The rising incidence of idiopathic pulmonary fibrosis in the U.K. Thorax 2011; 66: 462-467.

12 Hutchinson JP, McKeever TM, Fogarty AW, et al. Increasing global mortality from idiopathic pulmonary fibrosis in the twenty-first century. Ann Am Thorac Soc 2014; 11: 1176-1185.

13 Collard HR, Tino G, Noble PW, et al. Patient experiences with pulmonary fibrosis. Respir Med 2007; 101: $1350-1354$. 
14 Lokke A, Hilberg O, Tonnesen P, et al. Direct and indirect economic and health consequences of COPD in Denmark: a national register-based study: 1998-2010. BMJ Open 2014; 4: e004069-2013-004069.

15 Morell F, Esser D, Lim J, et al. Treatment patterns, resource use and costs of idiopathic pulmonary fibrosis in Spain - results of a Delphi Panel. BMC Pulm Med 2016; 16: 7-016-0168-6.

16 Rinciog $\mathrm{C}$, Watkins $\mathrm{M}$, Chang $\mathrm{S}$, et al. A cost-effectiveness analysis of nintedanib in idiopathic pulmonary fibrosis in the UK. Pharmacoeconomics 2017; 35: 479-491.

17 Fisher M, Nathan SD, Hill C, et al. Predicting life expectancy for pirfenidone in idiopathic pulmonary fibrosis. J Manag Care Spec Pharm 2017; 23: 3-b Suppl, S17-S24. 